\title{
17
}

\section{Meeting the Challenges of Integrative Learning: The Nexia Concept}

Jane Love

Furman University

Integrative learning challenges faculty developers to facilitate integrative and connective experiences not only for students, but for faculty as well. For many faculty, curricular requirements impede connective teaching, and the widespread assumption that connectivity must be taught on the course level also limits their ability to enrich students' learning through diverse perspectives and interactions. Nexia is an approach to this problem based on the concept of ad hoc connectivity, or small-scale, focused, short-term connections that allow students from two or more courses to interact around points of interest to both classes. By releasing connective teaching from expensive curricular constraints, the Nexia approach enables faculty and students to share interdisciplinary, integrative learning experiences within existing curricula.

The courses being given at any moment on a campus represent any number of rich potential conversations within and across the disciplines. But since students experience these conversations only as a series of monologues, the conversations become actual only for the minority who can reconstruct them on their own. (Graff, 1992, p. 106)

Coming to Furman University from teaching at a community college and a large research institution, I first encountered the phrase liberal arts moment as used by both faculty and students to refer to just such an experience as Graff describes. What struck me about the usage of this phrase was the aura of preciousness surrounding it: For students, it was accompanied by surprise and delight, and for faculty as well, but for the latter these feelings were cast in 
more subdued tones of nostalgia for their own such moments and worldweariness, in recognition, I thought, of the elusive, capricious, and serendipitous integration of such moments. I could sense my colleagues thinking, "It's working; it's actually working?" and surmised that the "it" was the alchemical magic of liberal learning. Every conversation I recall having with colleagues about liberal arts moments seemed redolent with the unspoken yet shared knowledge of initiates, and the tacit understanding that these moments visit those whose deserving nature is thereby revealed as such.

In my early days at Furman, I often wondered where the tools for conjuring liberal arts moments were stored away, and what secret password was used to access them. I still wonder where in our institutional mission statement is the clear intention to teach students to connect disparate ideas on their own. At what point in their careers do liberal arts faculty profess and examine their intention to help students integrate their learning? What role can or should faculty developers and teaching and learning centers play in supporting this intention?

\section{Defining the Problem: Initial Steps}

Six years ago, when I first began thinking about these questions, the conversation about integrative learning had not yet appeared on Furman's radar, although faculty interest in connecting knowledge and disciplines through creative new courses already had an impressive history. Despite Furman's rigid and weighty general education curriculum, which consumed the better part of both students' and the faculty's time and energy in introductory-level departmental courses, individual faculty members had managed to design and teach innovative, experimental courses that brought together faculty from two or more departments in highly imaginative ways. The fate of these courses ultimately depended on whether or how they were able to meet general education requirements, so many of these efforts flourished for a brief semester or two before fading away. It wasn't that students weren't interested in these courses, but that they had no room left in their course schedules for them after meeting both general education and major requirements.

Clearly, the curriculum was unable to support the faculty's recognition of the value of connectivity. Faculty time and effort in developing and teaching these courses was not rewarded, and student time and effort in taking courses that did not count toward a major or the general education requirement was not specifically valued either. The institutional message seemed to be that connective, integrative learning is the icing on the cake, nice for an academically ludic curricular interlude amidst the more serious work of tapping 
departmental silos. Furman was far from unique in any of these respects. The time, effort, and expense associated with designing and teaching interdisciplinary courses pose challenges to virtually every institution, yet faculty interest in teaching these courses seems to outpace the curricular transformations that might reduce the friction between requirements and connective teaching. Indeed, this problem may well be endemic to the nature of educational institutions, whose structures, like the form of a sonnet, both enable and contain the intellectual life they nurture.

\section{Refining the Problem: Recent Research}

The Association of American Colleges and Universities and The Carnegie Foundation for the Advancement of Teaching have been particularly diligent in articulating this problem and in soliciting solutions. In their jointly sponsored three-year Integrative Learning Project, projects undertaken by $10 \mathrm{di}$ verse institutions developed "advanced models and strategies to help students pursue learning in more intentional, connected ways" (The Carnegie Foundation, 2006). The projects (whose descriptions and outcomes are found in Huber et al., 2007) reveal the wide scope of connectivity within higher education, ranging from learning communities at the College of San Mateo, to an integrated capstone course at the Massachusetts College of Liberal Arts, to electronic portfolios at Portland State University. This broad range of initiatives, however, is implicit in the way the project's organizers answer the question, "What is integrative learning?"

Fostering students' abilities to integrate learning-across courses, over time, and between campus and community life-is one of the most important goals and challenges of higher education. The undergraduate experience can be a fragmented landscape of general education courses, preparation for the major, cocurricular activities, and "the real world" beyond the campus. But an emphasis on integrative learning can help undergraduates put the pieces together and develop habits of mind that prepare them to make informed judgments in the conduct of personal, professional, and civic life. (Huber \& Hutchings, 2004, p. 13)

One should anticipate that anything bearing the modifier "integrative" will tend to sprout tendrils of connectivity in every direction as it kudzus across the curriculum and beyond. Indeed, the term integrative learning appears to display this tendency in higher education at the moment. The conceptual logic of 
integration itself demands its own recursive, reflexive implementation. It is not enough simply to provide integrative learning opportunities for students, nor to help students connect them. Consistent, sustainable integrative learning requires the integration of these opportunities by integratively thinking faculty and administrators within integratively organized institutions. In other words, the process of creating integrative student learning is not only one of supplementation, but primarily one of transformation, for institutions, administrators, and faculty alike. The risk is that integrative efforts will languish within the conceptual sterility of "Departments of Integration," the tendrilly green safely quarantined from the sacred silos.

Huber and Hutchings (2004) explicitly recognize this difficulty:

Many campuses today are creating opportunities for more integrative, connected learning. First-year seminars, learning communities, interdisciplinary studies, capstone experiences, portfolios, student self-assessment, and other innovations are increasingly in evidence. The bad news is that they often involve small numbers of students or exist in isolation, disconnected from other parts of the curriculum and from other reform efforts. Indeed, the very structures of academic life encourage students to see their courses as isolated requirements to complete.

How, then, can campuses help students pursue learning in more intentionally connected ways? What does such learning look like? How might it be shaped by emerging cultural realities and by new thinking about learning and teaching? (p. 1)

The final report of the Integrative Learning Project (Huber et al., 2007) offers a wealth of provocative and inspiring ideas for how different institutions might craft unique approaches to integrating integration through programs and initiatives, many of them placing faculty conversations and connections in the spotlight (notably Carleton College, LaGuardia Community College, Salve Regina University, and the University of Charleston). These forward-thinking projects do much to "integrate integration" by supporting faculty in creating integrative opportunities for students. What may be missing here, though, are opportunities for faculty to experience integrative thinking for themselves, not primarily as teachers or scholars defined by expertise, but as amateurs, lovers of thinking for its own sake. 


\section{Recursive Integration}

If integrative teaching and learning are to be authentic and sustainable, then faculty need to renew their sense of discovery and joy in making connections, and to allow these feelings to shape the integrative opportunities they create for students. Huber and Hutchings (2004) were aware of this need at the outset of the Integrative Learning Project:

Behind these developments is a move toward asking students to "go meta" with their learning in order to identify, assess, and strategize about next directions. But many educators would argue that students are unlikely to develop such habits of reflection and intentionality if faculty do not do the same. Helping students to "go meta" involves designing better opportunities for students to connect their learning within and among courses and contexts. It involves faculty getting smarter about the look and feel of integrative learning so that students' efforts can be recognized and fostered. And it also involves faculty modeling, through their teaching, the thoughtful approach to learning that they want their students to develop. (pp. 8-9)

The authors are describing here, I think, the recursive property of integration and the role it plays in faculty development to support integrative learning. The natural corollary to active, creative, ubiquitous student integration is active, creative, ubiquitous faculty integration, released from curricular constraints and expressed through teaching. Faculty should not have to imagine what integrative learning looks like and feels like. They should be able to share the integrative processes of intellectual life with and alongside their students, through, and as, their teaching. I would, then, put yet a finer point on the role of faculty in "modeling... [a] thoughtful approach to learning": I would say that faculty need opportunities and support to engage in their own integrative thinking and learning, and that they especially need ways to actively explore and express integration, both their own and their students', through their teaching. More than anything, they need easy, agile ways of doing this that can directly involve their students, quick ways that can move in real time with the pace of their thinking and emerging current events. Some curricula are intentionally designed to enable this, but even for these institutions, curricular requirements often inhibit faculty in their ability to seamlessly fuse teaching with the unfurling excitement of intellectual life, for both themselves and their students. The pedagogy of integrative learning requires creative alternatives for teaching connectively that work independently of curricula or programs, and that is where Nexia begins. 


\section{Ad Hoc Connectivity}

Initially, my idea was to help faculty at a small liberal arts institution, with limited resources and a limiting curriculum, bring the richness and excitement of cross-disciplinary connections to their classes without the time-consuming effort of designing, proposing, and teaching new courses. We often assume that teachable connections can only take place as full-fledged courses. My idea was to enable an interdisciplinary approach that works for creating courses, but also below the course level. In other words, instead of filtering potential connections for their suitability as course topics, why not include the smaller overlappings, convergences, and contiguities that could sustain a stimulating, enriching encounter between two or more classes for a shorter period of time?

For instance, a women's studies class exploring the difference between sex and gender might partner for a few days with a human physiology class to read Anne Fausto-Sterling's "The Five Sexes" (1993). It might be possible for the two classes to meet face to face, but it would not be necessary: They could just as easily use a blog or online discussion forum to compare and contrast disciplinary perspectives throughout the week. The two professors might choose to monitor the discussion closely, assigning students specific duties and topics and grading their efforts, or they might choose instead to have some students rotate as monitors, others as daily reporters who share a summary of the discussion in class meetings for reflection and analysis. Rather than grading their students' contributions, the professors might instead have each student identify a provocative question from the discussion for further research, either independently or in collaboration with a student from the other class.

In another example, students in neuroscience, psychology, information technology, and philosophy courses might cooperate to create an annotated bibliography on the ethics of artificial intelligence. Early in the connection, students might meet for a specially scheduled screening of the film $A I$ (Spielberg, 2001) or to discuss a short, provocative text assigned in all four courses. This event would allow students to begin to frame research questions that cut across their respective courses, creating multidisciplinary teams around shared interests and purposes. Faculty might help students to work consciously at the intersection of disciplines by designing a review process for including materials in the bibliography that requires students to justify their selections to their respective groups, explaining their disciplinary significance as well as their value to the interdisciplinary nature of the bibliography. The project might culminate with another plenary event that challenges students 
collaboratively to apply their knowledge and understanding to complex case studies, thus demonstrating for themselves and others their understanding of both disciplinary and integrative methodologies. An even more expansive version might invite students from humanities and fine arts classes to examine the role played by cultural, artistic, and historical representations of artificial intelligence in contemporary ethical understandings of its challenges.

These are just two examples, but the possibilities for teaching connections range from brief, virtual conversations of a day or two, with students from different classes using email or blogs to explore a shared text or topic from the perspectives of their respective courses, to longer, more structured crosscourse collaborations in which students form extended working relationships with students from other classes around a shared project.

The possibilities are indeed endless, and both logistically and pedagogically complex. I do not wish to imply that ad hoc connectivity (i.e., "connecting this to this" within the larger context of a course, or connections that operate below the organizational or curricular level of the course) is necessarily simple or easy; indeed, it will undoubtedly prove challenging on multiple levels. Regardless, these endless possibilities are, however, limited at the outset by faculty members' ability to see these connections in the conversations latent throughout the teaching of a day, a week, a term, from one side of campus to the other. The words of Gerald Graff that open this chapter are evocative for their suggestion that these unheard conversations might inform teaching and learning. Conversation is but a glimpse of thinking itself, not when preserved as knowledge, but when caught in flagrante delicto, as it were, in the act of being itself-spontaneous, fluid, inventive, speculative, and intrinsically, inherently ad hoc, anchored in specificity and enthralled by the moment. Perhaps the liberal arts moment is merely thinking catching itself in the act.

Conversations over lunch, at the gym, and at faculty or committee meetings often provide a faculty version of liberal arts moments, but just as often they lack the intentionality needed to see their influence expressed through teaching. Thematically organized curricular initiatives invite faculty to rethink their teaching from fresh perspectives, but also risk imposing confining programmatic requirements. Additionally, as a colleague recently opined, the connections that faculty think of on their own tend to remain within the cognitive and conceptual frameworks of their disciplines, thus defeating at least one purpose of connecting: the formation of new contexts, radical juxtapositions, and innovative ideas. The difficulty is not simply that connections do not occur, but that, when they do occur, we are missing a structure that recognizes the value of these connections and intentionally links them to teaching and learning, for faculty and students alike. Something more was needed. 


\section{Nexia: "Plugged" and "Unplugged"}

Nexia began as both the concept of teaching connectively below the curricular radar, as it were, and as a technique for helping faculty discover intriguing connections for teaching, for research, and for the sheer joy of connecting. The technique we began with, which we've come to call "speed-linking," is simple and, because it requires no software or other technological support, completely "unplugged": groups of faculty from different divisions (roughly a dozen, but more were better than fewer) gathered to find connections among themselves. Working quickly, faculty paired off with instructions to find a teachable connection between their courses within a set time limit (usually seven minutes), after which they found new partners and repeated the sequence. Participants kept track of their connections on a worksheet, and, after several iterations of pairing and connecting, the entire group convened to share results.

Two things were notable about these sessions: First, most faculty enjoyed them tremendously. Not surprisingly, they bridled a bit at being kept to time limits for each pairing, but otherwise, they found the process inherently rewarding, both as a way of socializing with colleagues and as a form of "intellectual yoga."

The second, and perhaps more interesting, feature noted was the fascinating meta-connections that would emerge during the full-group processing at the end of the session. As faculty began to share the connections they'd discovered, others invariably chimed in with related connections, generating a hyper-connective dimension that stimulated provocative and lively discussion and insights into how knowledge is generalized across the curriculum. One faculty member noted that the speed-linking process was "how curriculum review ought to be done."

As useful and effective as these speed-linking sessions were, I was concerned that the face-to-face and personal nature of the sessions (which is one of their strengths) might well contribute to the institutional ephemerality of the connections. An ad hoc approach to connective teaching can have institutional significance only if a structure exists for recognizing, archiving, and building on the connections that faculty discover and articulate through their teaching. Developing such a structure became the next, and current, phase of Nexia.

I partnered with Kevin Treu, chair of Furman's computer science department, to seek funding from the Andrew W. Mellon Foundation for exploring and prototyping software that could both generate potential connections among faculty teaching and archive connections as they were implemented. 
Using an unstructured database of faculty-submitted, teaching-related documents (such as syllabi, lecture notes, course web sites, PowerPoint slides, articles, course proposals and descriptions, coupled with research materials related to teaching, such as manuscripts, grant proposals and reports, book reviews, etc.), we have been working to adapt semantic search technology. This software will be able to return conceptual matches for queries to the database, rather than word-for-word matches or results based on meta-data. For example, a query of "biodiversity" might return potential connections with courses in earth and environmental sciences (unsurprisingly) and biology, but also with courses in women's and gender studies (physiological conceptions of sex and gender, or ecofeminism), psychology (neurodiversity), economics (the sustainability of models of global development), mathematics (complexity theory), religion (creation myths), computer science (systems theory and selforganizing intelligence), and so on. The software is still in development, but preliminary trials on test databases have been encouraging and exciting.

Our vision for the software includes a web-based interface to facilitate queries and uploading of documents into the database so that faculty may search for potential connections at any time, without having to rely on faceto-face events or serendipitous encounters. A variety of filters will enable searches to return results based on faculty member, department (inclusive or exclusive), academic term, and other relevant information. Results will be weighted according to user-specified parameters and thresholds. Faculty will also be able to register connections discovered independently of the Nexia software, as well as implemented connections so that indexing of the database incorporates and reflects the value of these faculty-supplied variables while also maintaining a durable archive of their connections. A graphical interface will allow visualization of connections as clouds, clusters, nodes, or maps.

A software tool such as this has the potential to support several institutional and faculty development functions, such as discovery of new areas of interest for curricular planning, initiatives, projects, and outside funding proposals, or for identification of emerging learning communities. Its primary purpose, however, is to serve as a stethoscope for faculty straining to hear the latent conversations across Furman's campus, and we will soon have the opportunity to use it: In fall 2008, Furman will implement a new general education curriculum, one that emphasizes the value of integration and encourages connective teaching. Already, Furman's Center for Teaching and Engaged Learning is working with faculty to envision "the look and feel" of their connected courses. Already, we are learning that connectivity poses far more complicated, sensitive challenges for faculty development than we ever imagined in our quest for more liberal servings of liberal arts moments. 


\section{Recommendations}

The higher education community is still awakening to the importance of integration in undergraduate learning, and, along with it, the role of integration in faculty development. It is not too early, though, to share some preliminary recommendations for those wishing to explore creative ways of enhancing connectivity on their campuses.

For speed-linking or similar "unplugged" events, implementing the following recommendations will help to improve outcomes and maximize benefits:

- Create context. If possible, tie the event to a program or initiative that faculty are already thinking about, such as a curriculum change or an upcoming campus-wide theme.

- Capture connections. Provide faculty with worksheets for documenting the connections they discover at these events. Ask them to indicate which ones they find particularly compelling. Follow up on these with offers for consultation and support.

- Anticipate anxieties; customize support. Faculty who are interested in connecting their courses are often concerned about the additional time and effort that will be involved. To the extent possible, provide easy access to useful services and software, such as blogs and wikis. Investigate sources of student peer support on campus (e.g., the writing center or multimedia labs) for faculty who don't feel comfortable introducing their students to these technologies. Coordinated peer support may also facilitate group projects that involve students from two or more classes.

- Build community. Provide special recognition for faculty who actually teach their connections. Encourage them to create learning communities around shared issues, such as assessment of integrative learning and connective teaching.

- Connect institutionally. Summarize and share connections (with permission) with others who might benefit from this information (curriculum review or development groups, interdisciplinary studies departments, deans and provosts, grants offices, etc.) to highlight the institutional value of connective teaching.

Those interested in following the development of the Nexia software are welcome to visit our web site at http://nexia.furman.edu. We also encourage exploration and development of other software approaches to facilitated con- 
nectivity. The time is right for a community of developers to join together in envisioning technologies that will support, rather than replace, the integrative thinking skills our students so desperately need.

\section{Conclusion}

As we begin the work of creating pedagogies of integration, remembering what we already know and speculatively placing this knowledge within this new context may help to keep our expectations grounded and our perceptions clear. This is especially important as we approach connectivity, with its strong appeal to faculty imagination and its beguiling promise to leverage integrative benefits for student learning from existing curricula. Do not be deceived: Despite its warm and fuzzy surface, connectivity quickly cuts to the heart of deeply held personal assumptions and beliefs about the nature and value of teaching. Connectivity promises not so much to augment teaching as transform it and the teacher along with it. The vast array of possibilities for teaching connectively reflect the equally broad spectrum of teaching styles and philosophies. There is no one way of doing it; that is not what prompts transformation. Rather, the need to choose from among these possibilities brings to light our buried assumptions, values, and beliefs about teaching and about ourselves as teachers, often in confusing or perplexing ways. Connective teaching has much potential, not only as an integrative pedagogy, but as a path of deep reflection for faculty, a tool for conjuring liberal arts moments. As faculty and faculty developers begin the task of integrating integration, let the work proceed with care for what it asks of us, and with love for what it makes possible.

\section{Author Note}

The name "Nexia" derives from a conversation with Hal Abelson (MIT; co-founder of creativecommons.org) in 2003, in which he remarked on the similarity between our idea for a connectivity software tool and a 1950 science fiction novel by A. E. van Vogt, The Voyage of the Space Beagle. The central character of the novel, Dr. Elliott Grosvenor, is a pioneer in the field of "nexialism," or the science of integrating knowledge across disciplines. Nexialism is currently promoted by the Nexial Institute (www.nexial.org), with which Nexia has no formal relationship beyond the shared reference to van Vogt's novel. 


\section{References}

The Carnegie Foundation for the Advancement of Teaching. (2006). Integrative Learning Project: Opportunities to connect. Retrieved May 21, 2007, from www.carnegiefoundation.org/programs/index.asp?key=24

Fausto-Sterling, A. (1993, March/April). The five sexes: Why male and female are not enough. The Sciences, 20-24.

Graff, G. (1992). Beyond the culture wars: How teaching the conflicts can revitalize American education. New York, NY: W. W. Norton.

Huber, M. T., Brown, C., Hutchings, P., Gale, R., Miller, R., \& Breen, M. (Eds.). (2007). Integrative learning: Opportunities to connect (Public report of the Integrative Learning Project sponsored by the Association of American Colleges and Universities and The Carnegie Foundation for the Advancement of Teaching). Stanford, CA: The Carnegie Foundation for the Advancement of Teaching.

Huber, M. T., \& Hutchings, P. (2004). Integrative learning: Mapping the terrain. Washington, DC: Association of American Colleges and Universities.

Spielberg, S. (Director, Producer). (2001). AI [Motion picture]. United States: Warner Bros. 